\title{
Structural, optical and electrical properties of ZnO:Al thin films for optoelectronic applications
}

\author{
Youssef Ammaih • Abderrazak Lfakir • Bouchaib Hartiti • \\ Abderraouf Ridah • Philippe Thevenin - Meryane Siadat
}

Received: 18 March 2013 / Accepted: 16 August 2013 / Published online: 4 September 2013

(C) The Author(s) 2013. This article is published with open access at Springerlink.com

\begin{abstract}
Undoped and aluminum-doped $\mathrm{ZnO}$ thin films are prepared by the sol-gel spincoating process. Zinc acetate dihydrate, ethanol and mono-ethanolamine are used as precursor, solvent and stabilizer, respectively. The atomic percentage of dopant in solution were $[\mathrm{Al} / \mathrm{Zn}]=1 \%, 2 \%$ and $3 \%$. The effect of $\mathrm{Al}$ doping on the optical and electrical properties of $\mathrm{ZnO}$ films was investigated by X-ray diffraction (XRD), Four-Point probe technique and UV-visible spectrophotometery. The results from the X-ray diffraction show that the pure $\mathrm{ZnO}$ thin films had a polycrystalline structure of the hexagonal Wurtzite Type. A minimum resistivity of $3.3 \times 10^{-3} \Omega \cdot \mathrm{cm}$ was obtained for the film doped with $2 \mathrm{~mol} \%$ Al. Optical transmissions reveal a good transmittance within the visible wavelength spectrum region for all of the films. The value of the band gap is enhanced from $3.21 \mathrm{eV}$ (undoped $\mathrm{ZnO}$ ) to $3.273 \mathrm{eV}(\mathrm{Al} / \mathrm{Zn}=3 \%)$, the increase in the band gap can be explained by the Burstein-Moss effect.
\end{abstract}

Keywords ZnO:Al - Sol-gel · XRD $\cdot$ Transmittance $\cdot$ Optical band gap · Electrical resistivity

\section{Introduction}

In recent years, $\mathrm{ZnO}$ thin films has reached an important place in new technologies, and shows a wide range of scientific and technological applications (El Hichou et al. 2002; Bahedi et al. 2007; Dabos-Seignon et al. 2007). ZnO thin film is used in the fabrication of solar cells (Lin

Y. Ammaih $(\bowtie) \cdot$ A. Lfakir · B. Hartiti · A. Ridah

Laboratory LPMAER, Faculty of Science and Technology, Mohammedia, Morocco

e-mail: y.ammaih@gmail.com

P. Thevenin

Laboratory LMOPS, University of Lorraine, Lorraine, France

M. Siadat

Laboratory LASC, University of Lorraine, Lorraine, France 
et al. 2007), gas sensors (Lim et al. 2006) and catalysers (Miki-Yoshida et al. 2002). In the form of thin film, $\mathrm{ZnO}$ is a very promising alternative in flat display screens (Ghosh and Basu 1991) compared to tin-doped indium oxides (ITOs) which is a limited natural resource. When it is doped, $\mathrm{ZnO}$ film presents promising second-order nonlinear optical properties, which achieve the giant nonlinear optical effects about $50 \mathrm{pm} / \mathrm{V}$ (Ebothe et al. 2007). Many methods have been employed to prepare $\mathrm{ZnO}$ thin films like spray pyrolysis (Benny et al. 1999), molecular beam epitaxy (Feng et al. 2006), chemical vapor deposition (Funakubo et al. 1999), RF magnetron sputtering (Lai and Lee 2008) and sol-gel (Hwangbo et al. 2008). The latest method has the advantage to give a high surface morphology at lower crystallizing temperature. Doping is a very useful way for turning $\mathrm{ZnO}$ to an electronic material. Many dopants such as group I, V and rare earth elements have been used. Among those materials doping with $\mathrm{Al}$ elements can result in interesting structural, optical and electrical properties.

In this work, sol-gel technique was used to enhance the optoelectronic properties of $\mathrm{ZnO}$ thin films. $\left(\mathrm{Al}\left(\mathrm{NO}_{3}\right)_{3}, 9 \mathrm{H} 2 \mathrm{O}\right)$ dopant have been used. The coating solutions were prepared using zinc acetate dihydrate as precursor, 2-methoxyethanol and mono-ethanolamine (MEA) as solvent and stabilizer, respectively. $\mathrm{ZnO}$ thin films were deposited on glass substrates by spin coating technique. Structural and optical properties of $\mathrm{ZnO}$ thin films were investigated. The effect of nature and doping concentration on optical and electrical properties were too studied.

\section{Experimental details}

Undoped and $\mathrm{Al}$ doped $\mathrm{ZnO}$ (AZO) thin films have been deposited by sol-gel associated with spin coating method onto glass substrates. Zinc acetate dihydrate, 2-methoxyethanol, and monoethanolamine (MEA) were used as starting precursor, solvent, and sol stabilizer, respectively. The molar ratio of dopant (aluminum nitrate $\mathrm{Al}\left(\mathrm{NO}_{3}\right)_{3} 9 \mathrm{H}_{2} \mathrm{O}$ ) in the first solution was varied to give a $[\mathrm{Al} / \mathrm{Zn}]$ ratio between 0 and $3 \%$. The molar ratio of $[\mathrm{MEA} / \mathrm{Zn}]$ to zinc acetate dihydrate was maintained at 1 and the concentration of zinc acetate was $0.75 \mathrm{M}$ solutions were stirred at $60^{\circ} \mathrm{C}$ for $2 \mathrm{~h}$ to yield a clear and homogeneous solution, which served as the coating solution after cooling to room temperature. The coating solution was dropped into a glass substrate, which was rotated at 3,000 rpm for $30 \mathrm{~s}$. After depositing by spin coating, the film was dried at $200{ }^{\circ} \mathrm{C}$ for $10 \mathrm{mn}$ in a furnace to evaporate the solvent and remove organic residuals. The procedures from coating to drying were repeated five times. The films were then inserted into a tube furnace and annealed in air at $550{ }^{\circ} \mathrm{C}$ for $2 \mathrm{~h}$.

For characterization we have used a high-resolution X-ray diffraction for XRD patterns in the $\theta-2 \theta$ configuration with a copper anticathode $\left(\mathrm{CuKa}, 1.54 \mathrm{~A}^{\circ}\right)$. Sheet resistance was measured by the four point probe technique and the optical properties were monitored by transmittance using a Xe lamp in association with a $500 \mathrm{~mm}$ Yvon-Jobin HR460 spectrophotometer using a GaAs Photomultiplier tube detector optimized for the UV-VIS range (Table 1).

\section{Results and discussion}

\subsection{X-ray diffraction}

The crystal structure and orientation of $\mathrm{ZnO}$ thin film have been investigated by X-ray diffraction (XRD) method. The XRD pattern of the film is shown in Fig. 1. The XRD result suggests that the $\mathrm{ZnO}$ thin film has the polycrystalline structure. The film was crystallized 
Table 1 Crystallite size calculated from XRD

\begin{tabular}{lll}
\hline $2 \theta(\mathrm{deg})$ & Miller indice $(\mathrm{hkl})$ & Crystallite size $(\mathrm{nm})$ \\
\hline 34.44 & 002 & 78,94
\end{tabular}

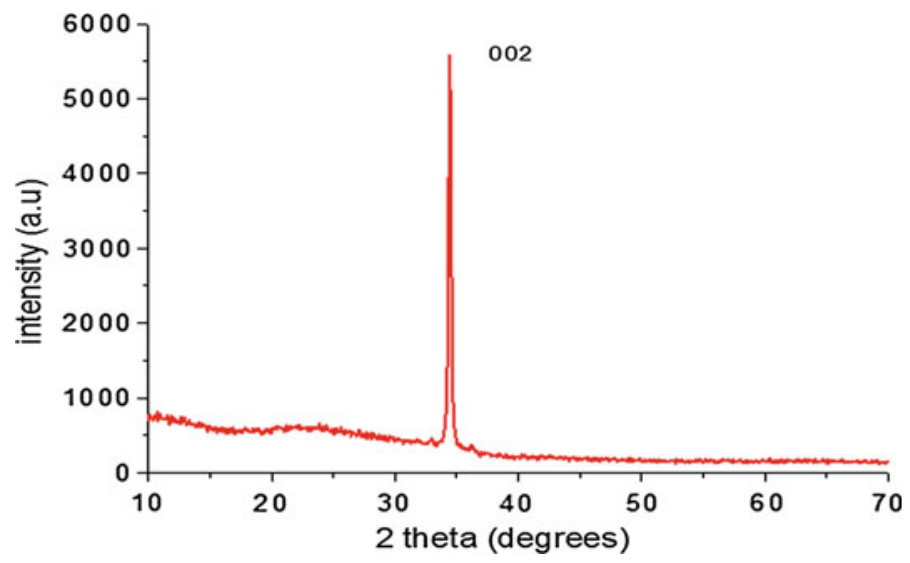

Fig. 1 X-ray diffraction pattern of the $\mathrm{ZnO}$ thin film

with the hexagonal wurtzite structure (Sun et al. 2005) and a strong preferred orientation $(5,574 \mathrm{au})$ along the direction (002) which is located at $2 \theta=34.44$ along the c axis with lattice parameters $\mathrm{a}=0.3258 \mathrm{~nm}$ and $\mathrm{c}=0.5225 \mathrm{~nm}$, very close to the theoretical values $\mathrm{a}=0.3256 \mathrm{~nm}$ and $\mathrm{c}=0.5237 \mathrm{~nm}$ (Minami et al. 1999).

The lattice constants -a- and -c- of the Wurtzite structure of $\mathrm{ZnO}$ can be calculated using the relations.

$$
c=\frac{\lambda}{\sin \theta} \quad \mathrm{a}=\sqrt{\frac{1}{3}} \frac{\lambda}{\sin \theta} \quad D_{h k l}=0.94 \frac{\lambda_{h k l}}{\beta_{\mathrm{hkl}} \cos \left(\theta_{h k l}\right)}
$$

$D_{\text {hkl }}$ is the crystallite diameter, $\lambda$ the wavelength, $\theta$ the Bragg angle, $\beta_{\text {hkl }}$ the full-width at half-maximum (FWHM) of the peak (Shah and Asiri 2009).

\subsection{Electrical properties}

Besides the optical properties, the electrical properties are also an important aspect of the performance of AZO thin films. The effects of doping aluminum concentration on the electrical resistivity of the $\mathrm{ZnO}$ thin films are presented in Fig. 2.

Figure 2 shows the evolution of the electrical resistivity of $\mathrm{ZnO}: \mathrm{Al}$ films depending on the doping level (Al). It is observed that the resistivity of the samples decreases $90.4 \times 10^{-4} \Omega \cdot \mathrm{cm}$ (undoped $\mathrm{ZnO}$ ) with increasing doping percentage and reached its lowest value $3.3 \times 10^{-3} \Omega \cdot \mathrm{cm}$ for doping Al $2 \%$, then it increases to $3.7 \times 10^{-4} \Omega \cdot \mathrm{cm}$ ( $3 \% \mathrm{Al}$ ). This decrease in resistivity with increasing doping concentration is due to the increased number of charge carriers (electrons) from donors $\mathrm{Al}^{3+}$ ions incorporated in the interstitial or substitutional sites of $\mathrm{Zn}^{2+}$ cations ( $\mathrm{Li}$ et al. 2009).

On the other hand, the electrical resistivity increases beyond $2 \% \mathrm{Al}$ may be due to the appearance of $\mathrm{Al}_{2} \mathrm{O}_{3}$ phase gives rise to the formation of an alloy instead of a doping ( $\mathrm{An}$ et al. 2008). This drastic reduction in mobility can be explained by the segregation of dopants at the grain boundaries. It seems that the micro-mechanism of the influence of doping is quite 


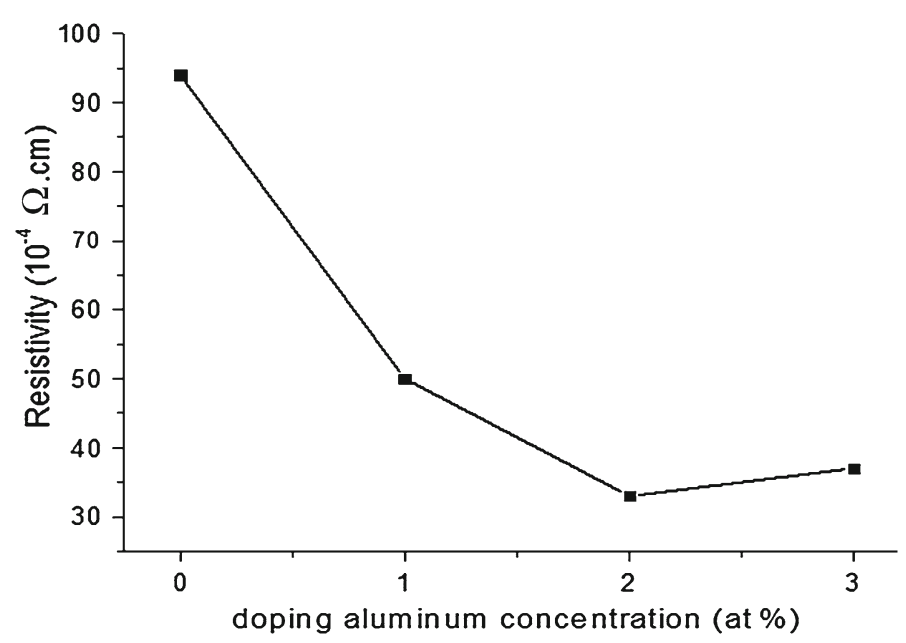

Fig. 2 Sheet resistance of undoped and $\mathrm{Al}$ doped $\mathrm{ZnO}$ films at various (at \%)

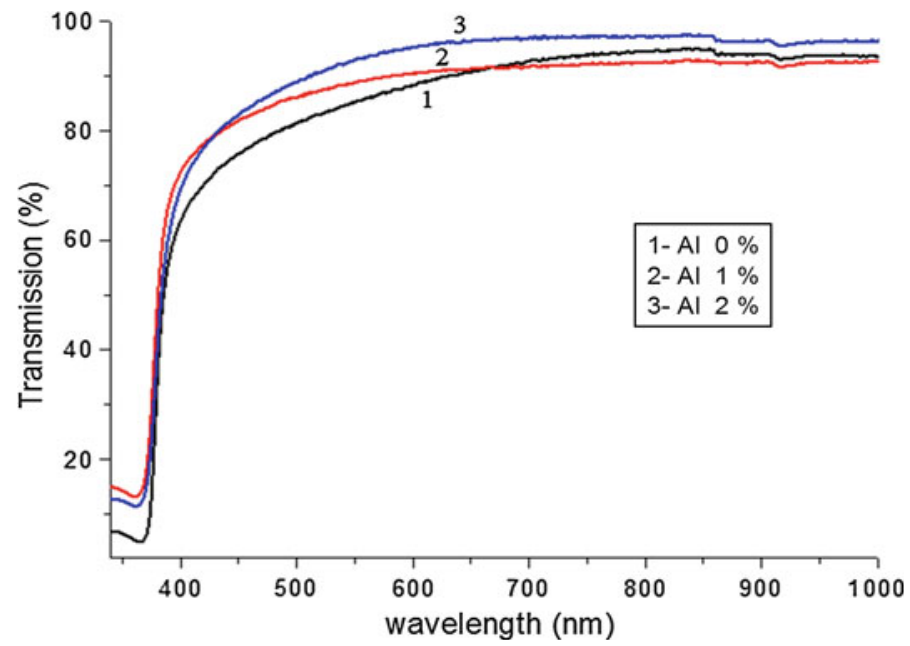

Fig. 3 Transmission and reflection spectra of AZO thin films deposited on glass substrates, for different values of concentration of aluminum dopant

complicated. Thus, we can conclude that beyond a doping concentration of $2 \% \mathrm{Al}$, there is a segregation of dopant atoms in non-crystalline regions that produces disturbances in the network. These defects act as diffusion centers giving rise to different diffusion mechanisms resulting in a sharp decrease in mobility and hence an increase in resistivity.

\subsection{Optical properties}

The transmittance of the deposited films with different $\mathrm{Al}$ content was measured at room temperature and the resulting transmittance spectra was shown in Fig. 3. It may be seen that all the films are highly transparent over the visible and near infrared regions from 350 to $800 \mathrm{~nm}$. 


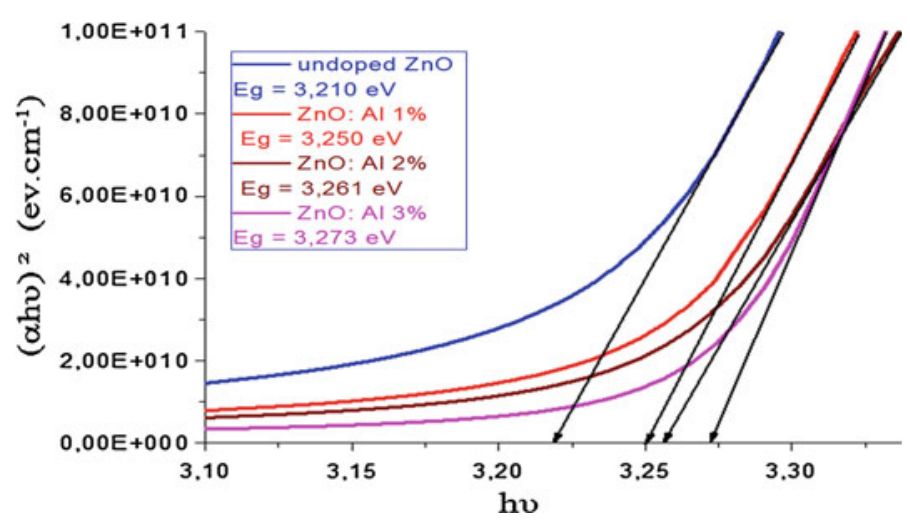

Fig. 4 Plot of $(\alpha$ hv $) 2$ and energy of the incident photon for films prepared at different aluminum doping concentration in the starting solution

The effect of $\mathrm{Al}$ doping on optical properties of $\mathrm{ZnO}$ films has been studied. In the present work, the average transmittance of all the deposited films varies from 80 to $90 \%$ in the wavelength range from 350 to $800 \mathrm{~nm}$. These results clearly show that this material can be used as a transparent oxide in solar cells.

From the transmission curve as a function of the wavelength we can represent the variation of $(\alpha h v)^{2}$ with $(h v)$ for calculated the band gap Eg, from the following equation (Daneshvar et al. 2003).

$$
(\alpha \mathrm{h} v)^{2}=\mathrm{B}(\mathrm{h} v-\mathrm{Eg})=\mathrm{f}(\mathrm{h} v),
$$

where $\mathrm{h} v$ is the energy of incident photons, Eg the optical gap and B is a constant.

Figure 4 shows the energy gaps for undoped $\mathrm{ZnO}$ and doped with a $(1,2,3 \%)$ aluminum. An obvious increase is observed for the values of the energy gap with the increase in the concentration of aluminum. This increase is explained by the preposition that the $\mathrm{ZnO}: \mathrm{Al}$ films are semiconductors in which the Fermi level lies in the conducive band which means that the levels at the bottom of the conductivity band are occupied by electrons and the shielding of electronic traveling to these levels is termed the Burstein-Moss effect (Moss 1954).

\section{Conclusions}

X-ray diffraction studies showed that the films are polycrystalline and the peaks fit well to the hexagonal wurtzite structure with a preferred orientation along the (002) direction which is located at $2 \theta=34.44$ along the $\mathrm{c}$ axis.

The effects of different aluminum concentrations on the electrical resistivity and optical transparency of the films were studied.

The electrical resistivity of $\mathrm{ZnO}: \mathrm{Al}$ films depending on the doping level ( $\mathrm{Al})$. It is observed that the resistivity of the samples decreases with increasing doping percentage and reached its lowest value $3.3 \times 10^{-3} \Omega \cdot \mathrm{cm}$ for doping $\mathrm{Al} 2 \%$.

The optical properties we can see the transmission increases with the increase in concentration of doping aluminum, the highest transmission is observed at (2\%) doping.

Optical transmissions reveal a good transmittance within the visible wavelength spectrum region for all of the films. The value of the band gap is enhanced from $3.21 \mathrm{eV}$ (undoped $\mathrm{ZnO})$ to $3.273 \mathrm{eV}$ ( $\mathrm{ZnO}: \mathrm{Al} 3 \%)$. The increase in the band gap can be explained by the Burstein-Moss effect. 
Acknowledgments This work was partially funded in project HORIZON from AUF under number (59113PS019). The author thanks" members of LMOPS lab for their help during stays of Profs HARTITI \& LFAKIR at Lorraine University

Open Access This article is distributed under the terms of the Creative Commons Attribution License which permits any use, distribution, and reproduction in any medium, provided the original author(s) and the source are credited.

\section{References}

An, K.-S., Cho, W., Lee, B.K., Lee, S.S., Kim, C.G.: Atomic layer deposition of undoped and Al-doped ZnO thin films using the $\mathrm{Zn}$ alkoxide precursor methylzinc isopropoxide. J. Nanosci. Nanotechnol. 8, 4856-4859 (2008)

Bahedi, K., Addou, M., El Jouad, M., Sofiani, Z., EL Oauzzani, H., Sahraoui, B.: Influence of size effect and sputtering conditions on the crystallinity and optical properties of $\mathrm{ZnO}$ thin films. Opt. Commun. 269(2), 346-350 (2007)

Benny, J., Gopchandran, K.G., Manoj, P.K., Koshy, P., Vaidyan, V.K.: Optical and electrical properties of zinc oxide films prepared by spray pyrolysis. Bull. Mater. Sci. 22(5), 921-926 (1999)

Daneshvar, N., Salari, D., Khataee, A.R.: Photocatalytic degradation of azo dye acid red 14 in water: investigation of the effect of operational parameters. J. Photochem. Photobiol. A: Chem. 157, 111-116 (2003)

Ebothe, J., Miedzinski, R., Kapustianyk, V., Turko, B., Kulyk, B., Gruhn, W., et al.: Optical SHG for ZnO films with different morphology stimulated by UV-laser thermotreatment. J. Phys.: Conf. Ser. 79, 012001 (2007)

El Hichou, A., Bougrine, A., Bubendorff, J.L., et al.: Structural, optical and cathodoluminescence characteristics of sprayed undoped and florine-doped ZnO thin films. J. Semicond. Sci. Technol. 17, 607-613 (2002)

Feng, Y., Zhou, Y., Liu, Y., Zhang, G., Zhang, X.: Photoluminescence spectra of nano structured ZnO thin films. J. Lumin. 120, 233-236 (2006)

Funakubo, H., Mizutani, N., Yonetsu, M., Saiki, A., Shinozaki, K.: Orientation control of ZnO thin film prepared by CVD. J. Electroceram. 4, 25-32 (1999)

Ghosh, A., Basu, S.: Spray/CVD deposition and characterization of surface modified zinc oxide thick films for gas sensor. Mater. Chem. Phys. 27, 45-54 (1991)

Hwangbo, S., Lee, Y.J., Hwang, K.S.: Photoluminescence of ZnO layer on commercial glass substrate prepared by sol-gel process. Ceram. Int. 34, 1237-1239 (2008)

Kapustianyk, V., Turko, B., Kostruba, A., Sofiani, Z., Derkowska, B., Dabos-Seignon, S., Barwiński, B., Eliyashevskyi, Yu., Sahraoui, B.: Influence of size effect and sputtering conditions on the crystallinity and optical properties of $\mathrm{ZnO}$ thin films. Opt. Commun. 269, 346-350 (2007)

Lai, L.W., Lee, C.T.: Investigation of optical and electrical properties of $\mathrm{ZnO}$ thin films. Mater. Chem. Phys. 110, 393-396 (2008)

Li, X.Y., Li, H.J., Wang, Z.J., Xia, H., Xiong, Z.Y., Wang, J.X., Yang, B.C.: Effect of substrate temperature on the structural and optical properties of $\mathrm{ZnO}$ and $\mathrm{Al}$-doped $\mathrm{ZnO}$ thin films prepared by dc magnetron sputtering. Opt. Commun. 282, 247-252 (2009)

Lim H.J., Yong D., Oha Y.J.: Gas sensing properties of $\mathrm{ZnO}$ thin films prepared by microcontact printing. Sensor Actuator A, 125, 405-410 (2006)

Lin, W., Ma, R., Xue, J., Kang, B.: RF magnetron sputtered ZnO: Al thin films on glass substrates: a study of damp heat stability on their optical and electrical properties. Sol. Energy Mater. Sol. Cells 91, 1902-1905 (2007)

Miki-Yoshida, M., Collins-Martınez, V., Amezaga-Madrid, P., Aguilar-Elguezabal, A.: Thin films of photocatalytic TiO2 and $\mathrm{ZnO}$ deposited inside a tubing by spray pyrolysis. Thin Solid Films 419, 60-64 (2002)

Minami, T., Miyata, T., Yamamoto, T.: Stability of transparent conducting oxide films for use at high temperatures. J. Vac. Sci. Technol. A 17, 1822-1826 (1999)

Moss, T.S.: The Interpretation of the properties of indium antimonide. Proc. Phys. Soc. Lond. Sect. B 67, 775-782 (1954)

Shah, M.A., Asiri, M.A.: Simple route for zinc oxide nanorods. Int. J. Nanopart. 2(2), 49 (2009)

Sun, Y.W., Gospodyn, J., Kursa, P., Sit, J., DeCorby, R.G., Tsui, Y.Y.: Dense and porous ZnO thin films produced by pulsed laser deposition. J. Appl. Surf. Sci. 248, 392-396 (2005) 